
\title{
R Research Soure \\ From Natural Oils to Epoxy Resins: A New Paradigm in Renewable Performance Materials
}

\section{Dragana Radojčić}

Pittsburg State University

Jian Hong

Pittsburg State University

Zoran S. Petrovic ( $\triangle$ zpetrovic@pittstate.edu )

Pittsburg State University

\section{Research Article}

Keywords: Epoxidized oils, cationic polymerization, highly cross-linked epoxy resins

Posted Date: May 17th, 2021

DOl: https://doi.org/10.21203/rs.3.rs-518125/v1

License: (c) (1) This work is licensed under a Creative Commons Attribution 4.0 International License.

Read Full License

Version of Record: A version of this preprint was published at Journal of Polymers and the Environment on July 16th, 2021. See the published version at https://doi.org/10.1007/s10924-021-02228-w. 


\title{
From Natural Oils to Epoxy Resins: A New Paradigm in Renewable Performance Materials
}

\author{
Dragana Radojčić ${ }^{\dagger}$, Jian Hong and Zoran S Petrović* \\ Kansas Polymer Research Center, Pittsburg State University, Pittsburg, KS, USA
}

${ }^{\dagger}$ Current address: Johnson Controls Inc., Marinette, WI 54143, Radojcic.dragana@gmail.com

*Corresponding author: zpetrovic@pittstate.edu 


\begin{abstract}
The direct conversion of natural products to useful engineering materials is desirable from both economic and environmental considerations. We are describing the synthesis and properties of $100 \%$ oil-based epoxy resins generated from three epoxidized oils. The catalyst, tris(pentafluorophenyl)borane $\left(\mathrm{B}\left(\mathrm{C}_{6} \mathrm{~F}_{5}\right)_{3}\right)$ in toluene, allowed for controlled cationic polymerization at a very low concentration. Epoxidized oils (derived from triolein, soybean, and linseed oil) had varying epoxy content, rendering resins of different cross-link density. The polymerization was carried out at room temperature followed by post-curing at elevated temperature to speed up conversion. Epoxy resins were amorphous transparent glasses with glass transitions below glass transitions and hard rubbers above. Despite their high cross-link density, these materials show relatively low $\mathrm{T}_{\mathrm{g}}$ 's reflecting the aliphatic nature of fatty acids and the presence of plasticizing "dangling" chains. The structure of the triglyceride starting oils influenced the properties of the resulting materials: the more regular structure of triolein compared to the very heterogeneous structures of soybean and linseed oils seemed to have enhanced some properties of the polymer networks. These epoxy polymers are potentially useful as encapsulating and potting compounds for electronic applications.
\end{abstract}

\title{
Key Words
}

Epoxidized oils, cationic polymerization, highly cross-linked epoxy resins 


\section{Introduction}

The utilization of natural oils for the creation of new materials is important from both, the perspective of sustainability and economic viability. Moreover, triglycerides are the only abundant biomass derived feedstock with a carbon to hydrogen ratio similar to petroleum. Especially, epoxidized oils are an excellent platform for a range of chemical reactions that may lead to useful polymeric materials. The simplest way to convert epoxidized oils to new materials is through directly polymerization to a final product. While standard petrochemical epoxy resins with terminal epoxy groups are often cured with amines, internal epoxy groups in epoxidized oils do not readily react under normal curing conditions [1]. Curing with anhydrides proceeds well but the process requires longer time and heating [2-4]. Curing epoxidized oils with minute amount of catalyst directly to a $100 \%$ oil-based product offers some technological advantages such as speed, economics, and easy processing. Various catalysts were used to polymerize internal epoxies such as superacids, their salts or products (esters, complexes), and Lewis acids [5-8]. These ionic initiators are often not miscible with hydrophobic epoxidized oil, requiring polar solvents, which remain in the polymer gels and limit their performance and industrial use. In this case the ring opening of oxiranes is initiated by the protonation of the epoxy oxygen as exemplified by polymerization of epoxidized oils in the presence of a cationic catalyst:

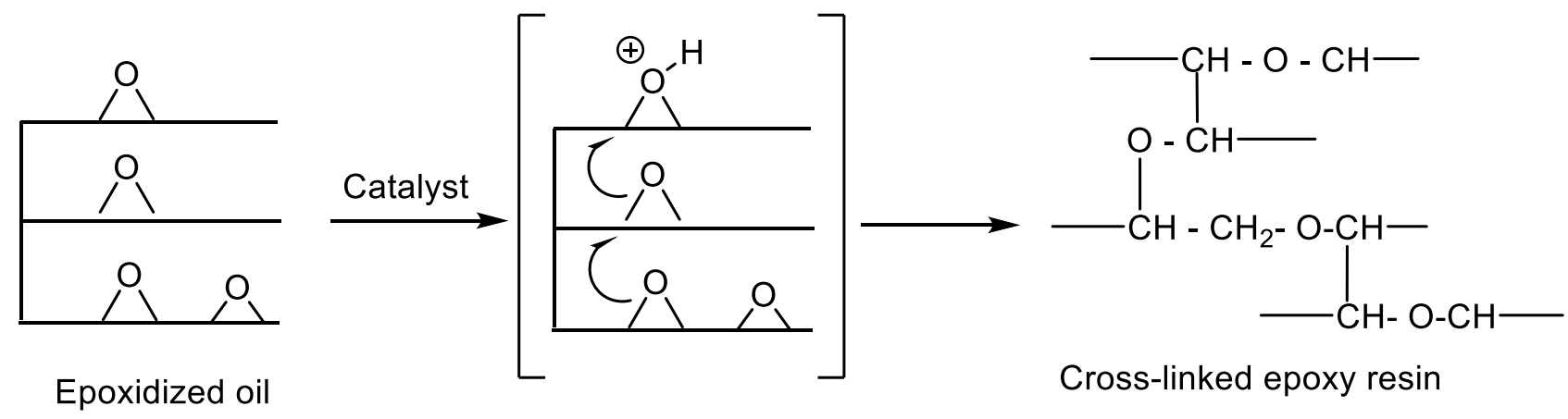

Scheme 1. Polymerization of epoxidized oil

The mechanism is complex, and it depends on many factors including the presence of a solvent, miscibility of components, temperature etc. The product of the cationic polymerization of simple oxiranes is often mixture of linear and cyclic oligomers. The reactions of epoxidized oils with superacids like fluoroboric acid $\left(\mathrm{HBF}_{4}\right)$ are very fast and highly exothermic, which was employed in producing oil-based foams [9], but could not be used to make cast resins and encapsulants for the protection of electronic components and possibly in $3 \mathrm{D}$ printing. We 
prepared with some success silica-filled epoxy resins by copolymerizing epoxidized soybean oil with butane diol in presence of fluoroboric acid [10]. So far, most studies on the cationic polymerization of oils have been carried out in solvents facilitating the ionic dissociation, absorb the excessive heat of reaction and improve the solubility of ionic initiators in non-polar oils. The use of a small amount of solvent, however, is advantageous as it allows for more facile control over the delivery of a small amount of catalyst. While high reaction rates are favorable for making foams, the polymerization must be slowed down to allow for enough time to cast the resin. Little attention has been paid in the literature to the structure of epoxy resins (polyethers) obtained by cationic polymerization of epoxidized oils. We have found a new catalyst, tris(pentafluorophenyl)borane $\left(\mathrm{B}\left(\mathrm{C}_{6} \mathrm{~F}_{5}\right)_{3}\right)$ in toluene, for cationic polymerization of epoxidized methyl oleate and studied the mechanism [11]. Tris(pentafluorophenyl)borane (also known as BCF) has been used in a variety of reactions including the polymerization of petrochemical epoxides, but, to the best of our knowledge not in polymerization of epoxidized vegetable oils [12].

An important aspect impacting the structure of polymers from epoxidized oils is the extent to which the reaction propagates. To obtain a cross-linked polymerized oil it would be enough to establish one bond between two triglyceride molecules, but higher degrees of polymerization may lead to higher cross-link density and better properties.

The objective of this work was to develop the polymerization process for a $100 \%$ oil-based material with useful properties and determine their structure. Our approach involved the cationic polymerization of epoxidized oils of different epoxy content and analysis of the degree of polymerization. It should be emphasized that these new polymers are essentially solid vegetable oils linked with ether bonds. Due to the high reaction rate controllable by temperature, the systems are potentially useful for 3D printing.

In this work we describe properties of materials made from epoxidized triolein (ETO) with three epoxy groups, epoxidized soybean oil (ESO) having on average four epoxy groups and epoxidized linseed oil (ELO) with about six epoxy groups per triglyceride. The cationic initiator BCF was used in this study as a novel curing agent for epoxidized oils. The efficiency of polymerization defined as the number of epoxy groups linked in a chain, was measured on degraded ETO samples. 


\section{Experimental}

$\underline{\text { Materials }}$

ESO, Drapex 6.8, with an epoxy oxygen content (EOC) of $6.8 \%$ was kindly supplied by Galata Chemicals. ELO, Epoxol 9-5, 9.4 \% EOC was obtained from ACS Technical Products, Griffith, IN, USA. High oleic algal oil with $\sim 95 \%$ oleic acid, practically the triolein, was kindly supplied by Solazyme. ETO, 5 \% EOC, was prepared in our laboratory using a published procedure [13]. $\mathrm{BCF}$ and dry toluene were purchased from Aldrich and used as supplied.

$\underline{\text { Methods }}$

Hydroxyl numbers (OH\#) were determined by the TSI method (ASTM E 1899-97). Epoxy oxygen content (EOC \%) was measured according to ASTM D1652 and Test method B by titration with standard $0.1 \mathrm{~N}$ perchloric acid in the presence of excess of tetraethyl ammonium bromide.

Size exclusion chromatography (SEC) was performed on a Waters gel permeation chromatograph, equipped with four Phenogel $5 \mu$ columns $\left(50,10^{2}, 10^{3}\right.$ and $\left.10^{4} \AA\right)$. The flow rate of tetrahydrofuran (THF) eluent was $1 \mathrm{~mL} / \mathrm{min}$ at $30{ }^{\circ} \mathrm{C}$. Also, SEC in conjunction with Dawn light scattering and refractive index $(\mathrm{RI})$ detectors from Wyatt were used to estimate absolute molar masses.

The reactivity of curing systems was evaluated from the gel point on a Control Stress Rheometer AR 2000 EX (TA Instruments) at $20{ }^{\circ} \mathrm{C}$.

Attenuated total reflection (ATR) Fourier Transform Infrared (FT-IR) spectra on solid samples were recorded using a Perkin-Elmer Spectrum Two-UATR Two spectrometer equipped with a diamond crystal. The recorded range was from 4000 to $500 \mathrm{~cm}^{-1}$, with $4 \mathrm{~cm}^{-1}$ resolution and 4 scan accumulation.

Tensile properties were measured on a Model 3367 tensile tester from Instron, according to ASTM D882-97.

Differential scanning calorimetry (DSC) was performed on a TA DSC Q100 at a heating rate of $10{ }^{\circ} \mathrm{C} /$ min under nitrogen. Thermogravimetric analysis (TGA) was performed on a TA Q500. Samples were heated under nitrogen using a heating ramp of $10.0^{\circ} \mathrm{C} / \mathrm{min}$ from 25 to $600{ }^{\circ} \mathrm{C}$. Thermomechanical analysis (TMA) was carried out on a TA Q400 from TA Instruments with a heating rate of $10^{\circ} \mathrm{C} / \mathrm{min}$ under nitrogen. Dynamic mechanical analysis (DMA) was carried out on a TA 2980 from TA Instruments. The testing was performed in the tension mode under 
nitrogen at a heating rate of $3^{\circ} \mathrm{C} / \mathrm{min}$ and a mechanical vibration frequency of $1 \mathrm{~Hz}$ (amplitude: $15 \mu \mathrm{m})$. For determination of activation energies of transitions, the samples were run at simultaneous frequencies of 3, 10 and $30 \mathrm{~Hz}$. A dielectric analyzer DEA 2070 from TA Instruments was used to study dielectric properties of films at six frequencies $\left(1-10^{5} \mathrm{~Hz}\right)$ at a heating rate of $3{ }^{\circ} \mathrm{C} / \mathrm{min}$. The sample thickness was approximately $0.7 \mathrm{~mm}$.

Swelling ratios were determined from volumes of the swollen samples at equilibrium and initial volumes. Sol fractions (SF) were the relative weight losses of the samples after solvent extraction. It was expressed in \% SF. $\left.\mathrm{SF}=\left[\left(\mathrm{W}_{0}-\mathrm{W}_{\mathrm{s}}\right) \times 100\right)\right] / \mathrm{W}_{0}$, where $\mathrm{W}_{0}$ and $\mathrm{W}_{\mathrm{s}}$ are the weights of the sample before and after extraction.

$\underline{\text { Synthesis of polymers }}$

The catalyst solution was prepared by dissolving $0.04 \mathrm{~g}$ of BCF in $1 \mathrm{~mL}$ dry toluene $(4 \%)$. BCF is solid and its toluene solution allows for more accurate delivery of the very low catalyst concentration in the mixture with epoxidized compounds. Polymerizations, however, were carried out without additional solvent addition: $10 \mathrm{~g}$ of epoxidized oil (ESO) and $200 \mu \mathrm{L}$ of catalyst solution were charged in a vial equipped with a magnetic stir bar. The concentration of BCF was $0.08 \mathrm{wt} . \%$. The mixture was poured into a mold and left to cure at room temperature for $60 \mathrm{~min}$. Post-curing at $100{ }^{\circ} \mathrm{C}$ for at least 12 hours was applied to ensure the completion of the reaction.

The gel point at $20{ }^{\circ} \mathrm{C}$ was reached in 5 minutes for ETO, 27 minutes for ESO and 43 min for ELO. When cured in an oven at $100{ }^{\circ} \mathrm{C}$, gelation occurred instantly. BCF is sensitive to moisture. We have not taken any precautions to exclude contact with air for practical reasons. However, freshly prepared catalyst solutions were necessary to obtain the best properties.

\section{Results and Discussion}

The first objective of this work was to utilize natural oil properties for making advanced materials for applications as casting resins and encapsulating compounds for electrical applications as well as potentially 3D printing systems. Pure vegetable oil material from epoxidized oil was tested as 3D printing material using a multi-component photo-initiating mixture and visible light, but material properties were not analyzed [14]. The structure of epoxidized oils used in this work is presented in Scheme 2. 


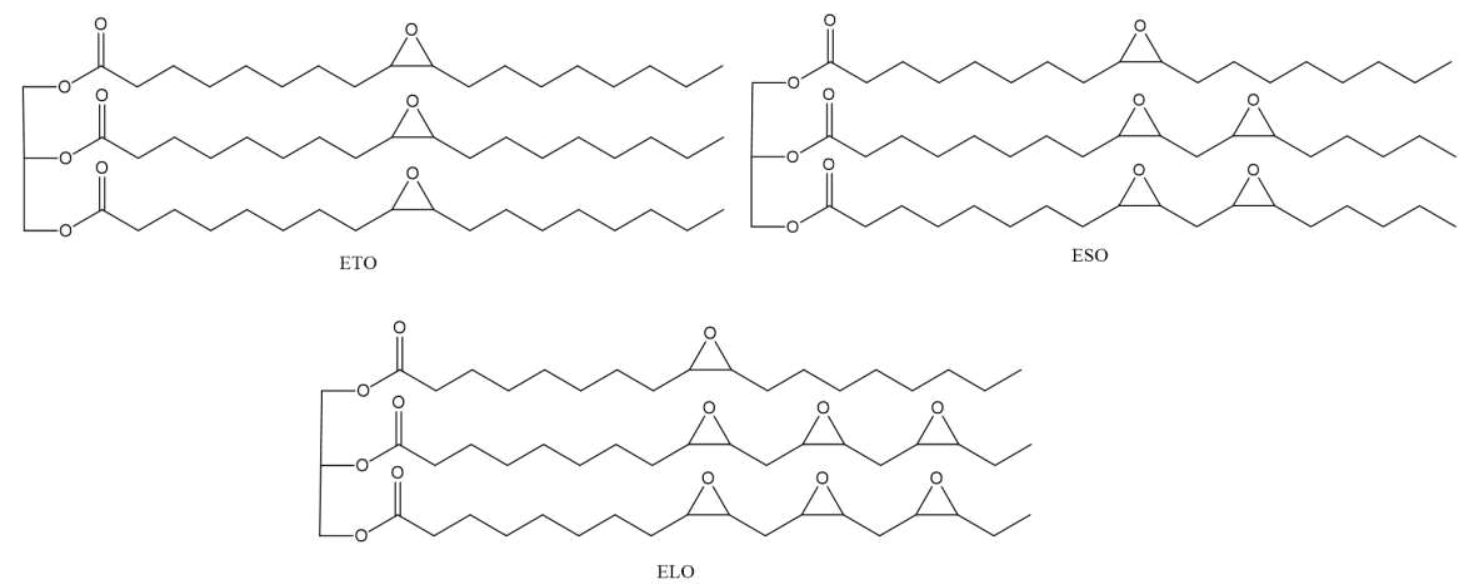

Scheme 2. Epoxidized oils used in this work

Oils are hydrophobic, low viscosity liquids, and have good oxidative thermal stability when double bonds are eliminated, but in cross-linked polymers they accommodate "dangling chains" which act as internal plasticizers [15].

Understanding the structure of the products requires the analysis of cationic polymerization of internal (disubstituted) epoxy groups. Since epoxy groups are bifunctional epoxidized oils display very high functionality. Basic characteristics of epoxidized oils are presented in Table 1.

Table 1. Properties of epoxidized oils used in this work

\begin{tabular}{cccccc}
\hline $\begin{array}{c}\text { Epoxidized } \\
\text { Oil Source }\end{array}$ & Designation & $\begin{array}{l}\text { EOC, } \\
\%\end{array}$ & $\begin{array}{l}\text { No. of epoxy groups } \\
\text { per triglyceride }\end{array}$ & Functionality & $\begin{array}{l}\text { Molar mass, } \\
\text { g/mol }\end{array}$ \\
\hline Triolein & ETO & 5 & 3 & 6 & $\sim 933$ \\
Soybean & ESO & 6.8 & 4 & 8 & $\sim 920$ \\
Linseed & ELO & 9.4 & 6 & 12 & $\sim 940$ \\
\hline
\end{tabular}

To understand differences between the oils used in this work, it is important to look at their composition (Table 2). During epoxidation saturated fatty acids, FA, will not be affected and may later act as dangling chains in polymerized networks.

Table 2. Typical composition of oils used in this work

\begin{tabular}{lccccc}
\hline Oil & $\begin{array}{c}\text { Palmitic, } \\
\%\end{array}$ & $\begin{array}{c}\text { Stearic, } \\
\%\end{array}$ & $\begin{array}{c}\text { Oleic, } \\
\%\end{array}$ & $\begin{array}{c}\text { Linoleic, } \\
\%\end{array}$ & $\begin{array}{c}\text { Linolenic, } \\
\%\end{array}$ \\
\hline Algal (Triolein) & 3 & - & 95 & 2 & - \\
Soybean & 11 & 4 & 23 & 52 & 6 \\
linseed & 5 & - & 23 & 16 & 54 \\
\hline
\end{tabular}

Due to high functionality, polymerization of epoxidized oils provide highly cross-linked networks. The observed cross-link density depends on the efficiency of the polymerization, formation of 
loops, cyclic compounds, and side reactions. Whereas linseed and soybean oils are very heterogeneous in composition, triolein is very regular. Fig. 1 displays infrared spectra of polymerized epoxidized oils and liquid ETO as a reference. The spectra show the presence of weak hydroxyl peaks in all polymers at $3500 \mathrm{~cm}^{-1}$, possibly because of ring opening by moisture from air and some hydroxyls from the starting epoxidized oils. Cyclic epoxy bands detected at 828 and $844 \mathrm{~cm}^{-1}$ (asymmetric C-O-C stretch) in ETO are absent or barely visible in polymerized oils, but the degree of conversion of epoxy groups is difficult to determine. Other prominent bands are C-H stretches at 2924 and 2852, ester C=O at 1743, methyl C-H at 1462 and 1378; C-O (ester) at 1247 and 1154; ether C-O -C asymmetric stretch at 1076 and skeletal C-C wag at $723 \mathrm{~cm}^{-1}$.

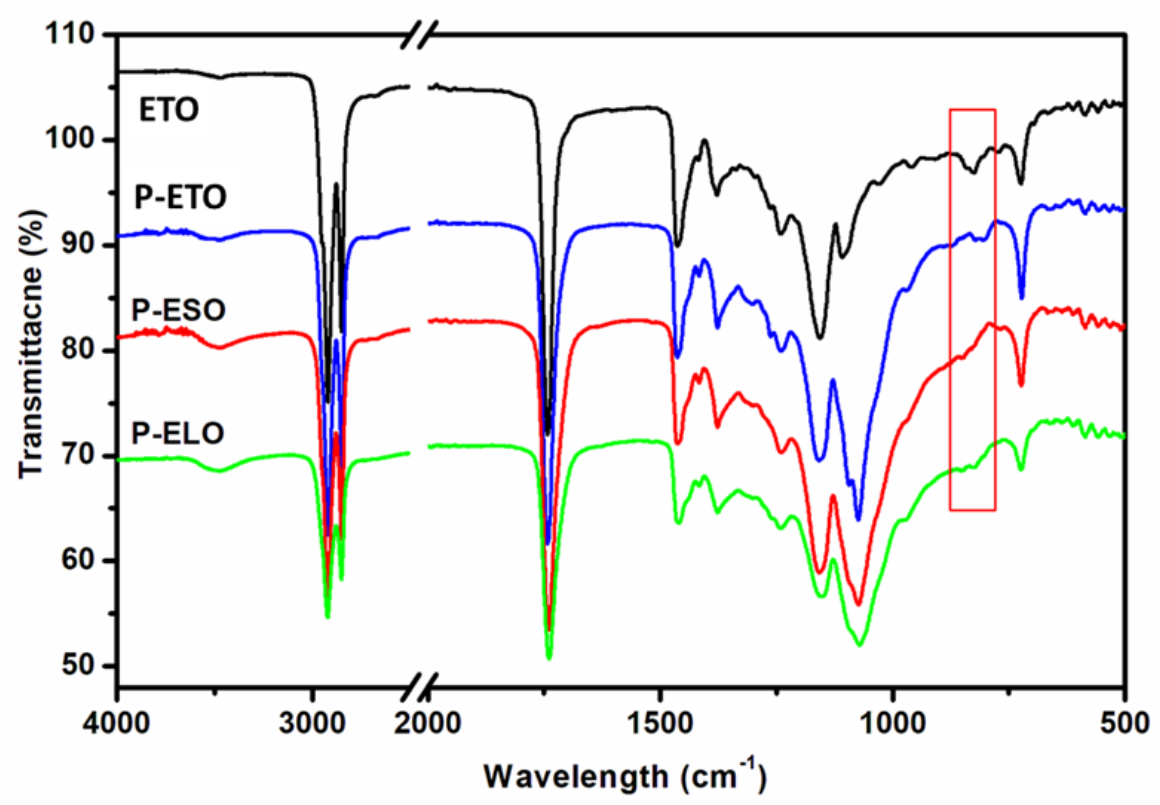

Fig. 1 Infrared spectra of P-ETO, P-ESO, P-ELO, and ETO reference. Epoxy bands if present should appear in the box.

The products from the cationic polymerization of epoxidized methyl oleate in presence of fluorosulfonic acid listed various cyclics (dioxane, dioxolane), linear ketones and polyether oligomers [8]. Cyclic structures also participate in network formation, but internal cycles within the same triglyceride, decrease cross-link density. Whereas epoxy groups in ETO are regularly distributed, some fatty acid chains in ESO and ELO may have several epoxy groups separated by one $\mathrm{CH}_{2}$ group and some are without epoxy groups, producing regions in networks of different cross-link density. Ring opening of epoxy groups in close proximity as found in epoxidized 
linoleic and linolenic acids, often lead to the formation of 5- membered or larger rings, thus reducing cross-link density $[8,16]$. In the absence of rings, linear polymer chains would produce extremely high cross-link density as depicted in Scheme 3, with molecular weights between cross-links, $M_{c}$, of around 230. Such a low $M_{c}$ should produce rather high glass transition temperatures, $\mathrm{T}_{\mathrm{g}}$, even for fully aliphatic amorphous networks.

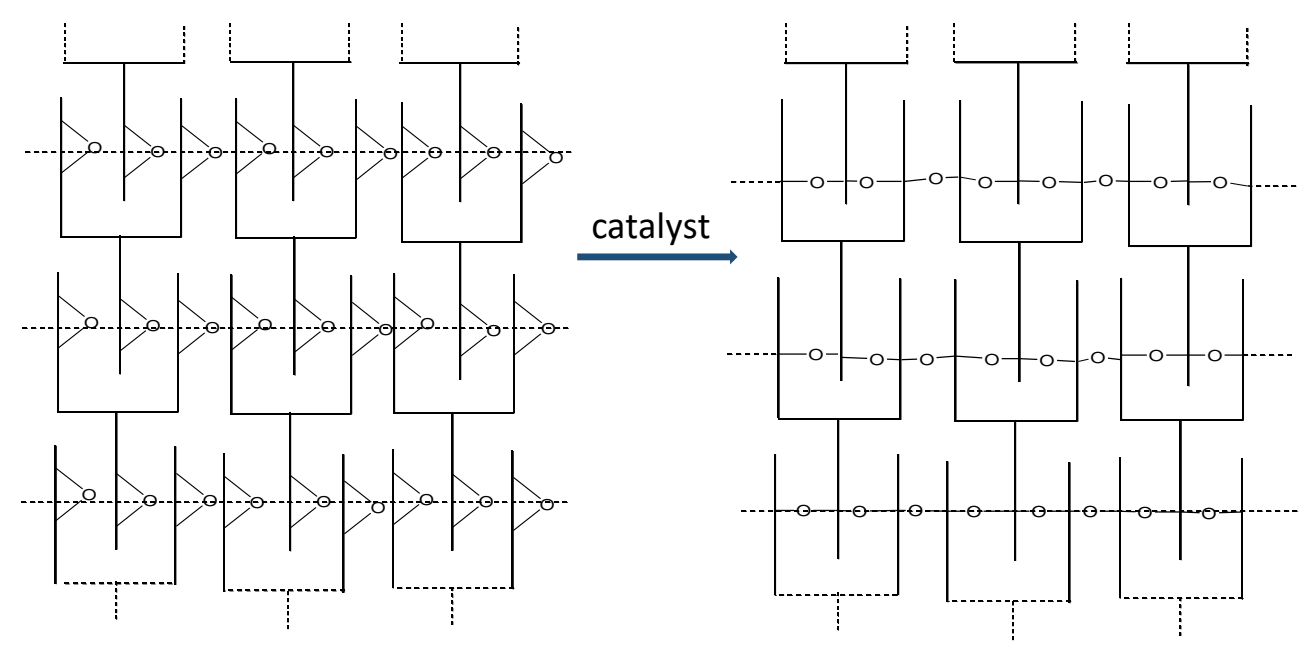

Scheme 3. Graphic representation of the formation of a polymer network from epoxidized triolein

The presented structure in Scheme 3 is highly ordered to illustrate the highest possible cross-link density. However, the polymerization reaction takes place in the disordered liquid state and may be disrupted in many ways, producing ineffective loops or unreactive species in side reactions.

\section{Estimation of efficiency of cationic polymerization with BCF}

The basic question related to the cross-link density is how many epoxy groups have reacted before the chain was terminated. The degree of polymerization can be assessed by hydrolysis or methanolysis of ester bonds in polymerized triglycerides and measuring molecular weights of the resulting polyethers. This approach is only valid for the polymerized ETO, while linoleic and linolenic epoxy groups in ESO and ELO introduce additional ether cross-links that are unaffected by hydrolysis. The process is illustrated in Scheme 4. If methanolysis of the networks is carried out in the presence of $\mathrm{KOH}$, polymerized ETO produces polymerized methyloleate (PMEO), while linoleic acid rich ESO results in a gel or partial gel. Accordingly, we observed the product of ETO methanolysis as a viscous liquid, depicting by FT-IR the presence of OH groups and the absence of epoxy groups. SEC of P-MEO obtained after methanolysis of P-ETO and 
compared to starting material ETO and monomeric EMO, is displayed in Fig. 2. It shows the presence of about $5 \%$ monomers (probably methyl palmitate), $4.7 \%$ dimers, some trimers, and tetramers and around $90 \%$ of higher oligomers. The average molecular weight was 4700 and the highest molecular weight was around 27,000 corresponding to 80 monomer units (epoxidized methyl oleate). This confirms that BCF is a very efficient catalyst for polymerization of epoxidized oils. Hydroxyls may come from the moisture in air and the monomer, but they are always present in epoxidized oils due to some ring opening with acids during the epoxidation process. Accordingly, a small OH peak was observed in the FT-IR spectra of epoxidized oil and epoxidized methyl oleate. The presence of $\mathrm{OH}$ groups in the starting reaction mixture favors linear chains vs. predominantly cyclics formed in the absence of hydroxyls. It is interesting that direct polymerization of epoxidized methyl oleate catalyzed by BCF gave a very similar SEC curve [11].
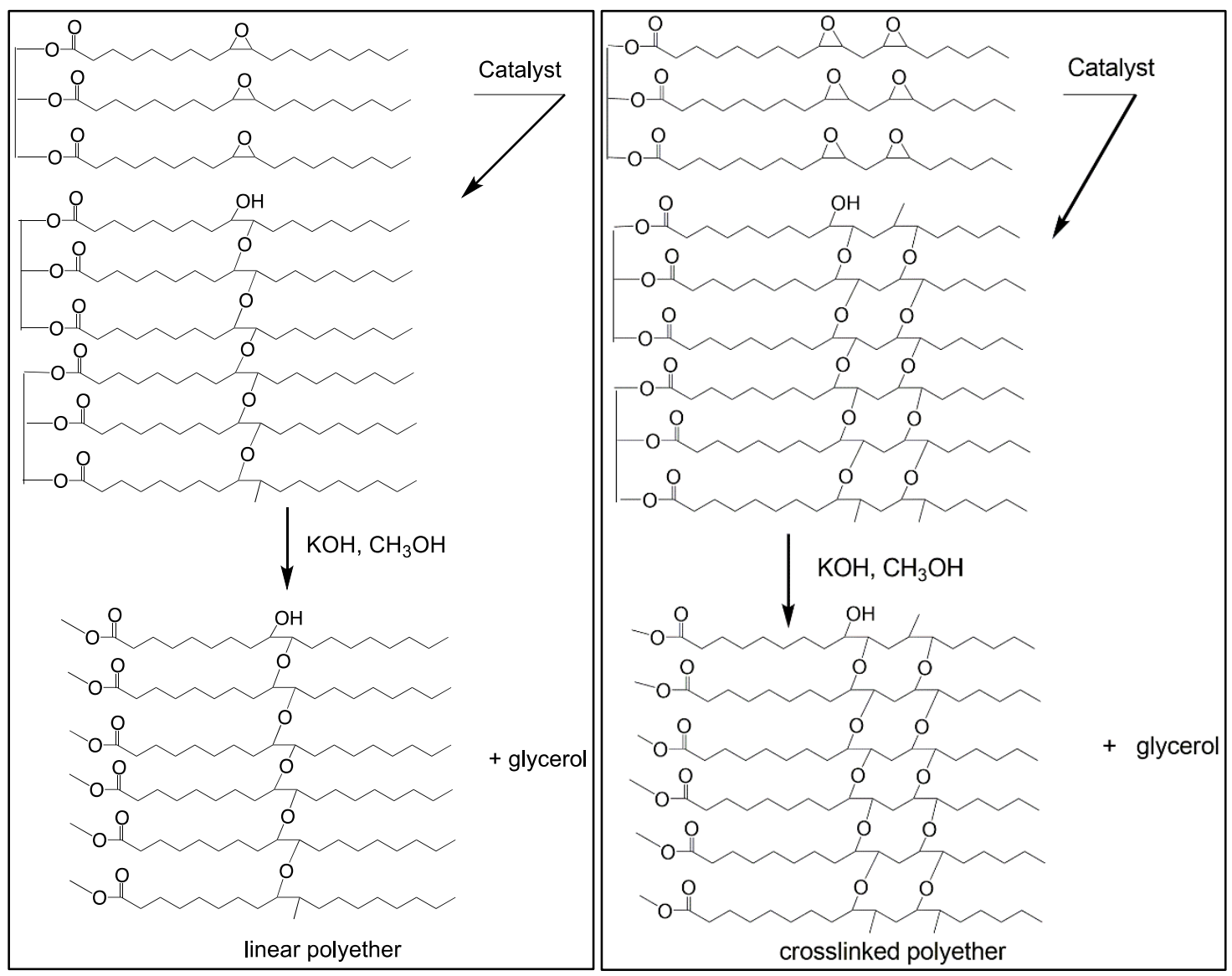

Scheme 4. Illustration of the process for the synthesis of networks and subsequent methanolysis 


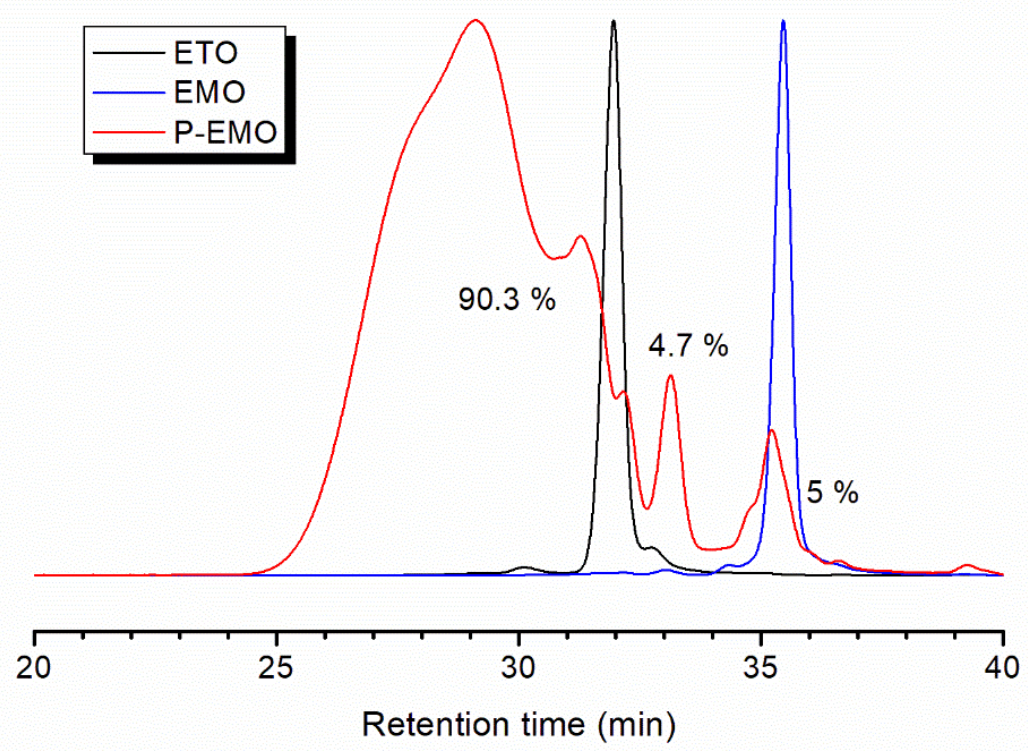

Fig. 2 SEC curves for the hydrolyzed ETO polymer (P-EMO), epoxidized triolein (ETO) and epoxidized methyl oleate (EMO).

\section{Physical properties of polymerized epoxidized oils}

Our cured epoxidized oils are transparent materials with light brown color. The intensity of the color depends the sample thickness and curing conditions, being darker when post-cured at elevated temperatures. While the density of oils (triolein, SBO and LO) is about $0.92 \mathrm{~g} / \mathrm{cm}^{3}$ at room temperature, the densities of epoxidized oils are higher: $0.99 \mathrm{~g} / \mathrm{cm}^{3}$ for ESO, $1.03 \mathrm{~g} / \mathrm{cm}^{3}$ for ELO and $0.96 \mathrm{~g} / \mathrm{cm}^{3}$ for ETO (solid at $25^{\circ} \mathrm{C}$ ). Cross-linking resulted in higher densities of polymerized epoxidized oils: $0.99 \mathrm{~g} / \mathrm{cm}^{3}$ for P-ETO (calculated density from group contribution method $^{17}$ is $\left.1.09 \mathrm{~g} / \mathrm{cm}^{3}\right), 1.05 \mathrm{~g} / \mathrm{cm}^{3}$ for P-ESO and $1.1 \mathrm{~g} / \mathrm{cm}^{3}$ for P-ELO.

A solubility parameter $(\delta)$ for polymerized ETO of $19.4 \mathrm{MPa}^{1 / 2}$ was calculated using the group contribution method of van Krevelen [17]. The results of swelling studies in toluene $(\delta=18.3$ $\left.\mathrm{MPa}^{1 / 2}\right)$, methylene chloride $\left(\delta=20.2 \mathrm{MPa}^{1 / 2}\right)$ and dimethylformamide $\left(\delta=24.7 \mathrm{MPa}^{1 / 2}\right)$ is shown in Table 3. The largest swelling ratios were observed in methylene chloride and toluene (20-40 $\%$ ). The observed sol fractions of 2-3\% could be caused by impurities and possibly low molecular weight cyclics and unreacted species. Low sol fraction values reflect a high degree of conversion. 
Table 3. Swelling ratios and sol contents of cross-linked networks in different solvents.

\begin{tabular}{ccccccc}
\hline & \multicolumn{2}{c}{ Toluene } & \multicolumn{2}{c}{ DMF } & \multicolumn{2}{c}{ Methylene chloride } \\
\cline { 2 - 7 } Polymers & $\begin{array}{l}\text { Swelling } \\
\text { ratio }\end{array}$ & $\begin{array}{l}\text { Sol } \\
\text { content, } \\
\text { wt. \% }\end{array}$ & $\begin{array}{l}\text { Swelling } \\
\text { ratio }\end{array}$ & $\begin{array}{l}\text { Sol } \\
\text { content, } \\
\text { wt. \% }\end{array}$ & $\begin{array}{l}\text { Swelling } \\
\text { ratio }\end{array}$ & $\begin{array}{l}\text { Sol } \\
\text { content, } \\
\text { wt. \% }\end{array}$ \\
\hline P-ETO & 1.3 & 2 & 1.1 & 0 & 1.3 & 3 \\
P-ESO & 1.4 & 1 & 1.2 & 1 & 1.4 & 2 \\
P-ELO & 1.2 & 5 & 1.1 & 1 & 1.3 & 2 \\
\hline
\end{tabular}

DSC measurements revealed glass transitions below room temperature for P-ESO and P-ETO while P-ELO was rigid, glassy polymer below $44{ }^{\circ} \mathrm{C}$ (Fig. 3). In comparison, previously reported $\mathrm{T}_{\mathrm{g}}$ values for fluorosulfonic acid initiated cross-linked ESO fall between -16 and $-21{ }^{\circ} \mathrm{C}$ [18]. DSC $\mathrm{T}_{\mathrm{g}}$ value for our P-ELO of $44{ }^{\circ} \mathrm{C}$, is in line with reported $\mathrm{T}_{\mathrm{g}}$ from $\tan \delta$ (DMA) at 68 ${ }^{\circ} \mathrm{C}$ [19]. P-ESO and P-ETO glass transitions were at 3 and $5{ }^{\circ} \mathrm{C}$, respectively, i.e., they are rubbery at room temperature.

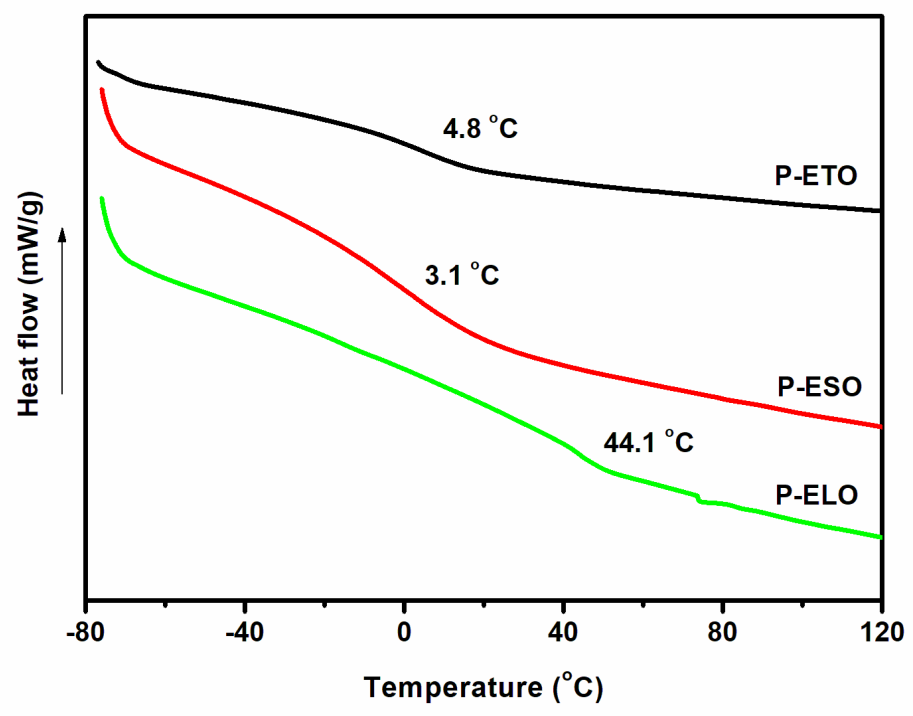

Fig. 3 DSC curves for polymerized P-ELO, P-ESO and P-ETO

The relatively low $\mathrm{T}_{\mathrm{g}}$ of P-ETO and P-ESO can be attributed to imperfect networks due to side reactions, the plasticizing effect of "dangling chains" with nine methylene groups in ETO, and some shorter and saturated fatty acid chains in ESO, and $2 \%$ remaining toluene from the catalyst. Given the relatively high content of saturated FA components and their assumed plasticizing effect in $\mathrm{ESO}$, the lower $\mathrm{T}_{\mathrm{g}}$ for P-ESO than in P-ETO despite higher EOC is not surprising. The higher $\mathrm{T}_{\mathrm{g}}$ of P-ELO is a result of higher cross-link density as the EOC in ELO amounts to almost twice compared to ETO (Table 1). 


\section{Thermomechanical analysis of polymers}

Thermomechanical analysis of polymers was used to determine the glass transition and thermal expansion coefficients in glassy and rubbery states. TMA curves shown in Fig. 4 were obtained on $1 \mathrm{~mm}$ thick samples. The slopes on the curves were low in the glassy state and increased in the rubbery state. Glass transition temperatures from the break on the curves were difficult to find with any precision. Coefficients of thermal linear expansion (CTLE) measured at $\sim 40{ }^{\circ} \mathrm{C}$ below and above glass transition temperature were around $140 \times 10^{-6} / \mathrm{K}$ (glassy) and $206 \times 10^{-6} / \mathrm{K}$ in the rubbery state for P-ETO, around $120 / 210 \times 10^{-6}$ for P-ESO and $114 / 180 \times 10^{-6}$ for P-ELO. Lower CTLE both in glassy and the rubbery state for ELO are due to considerably higher cross-link density.

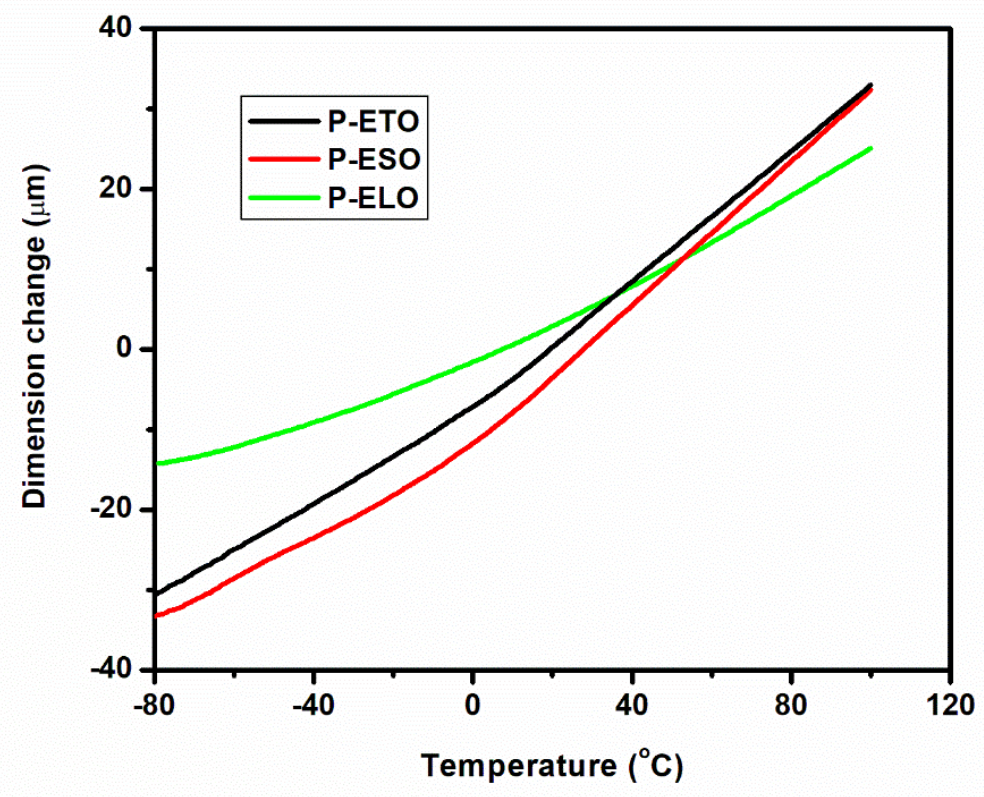

Fig. 4 Thermal expansion curves for polymerized P-ELO, P-ESO and P-ETO

\section{Relaxation properties of polymerized epoxidized oils}

Dynamic mechanical properties

Low glass transition of two polymerized epoxidized oils reflects high mobility of network chains. Dynamic mechanical and dielectric spectroscopy were used to observe transitions in these polymers. Fig. 5 illustrates dynamic mechanical behavior of the networks. Storage modulus, E', in the glassy state decreased quickly with temperature both in P-ETO and P-ELO but was more stable in P-ESO. It dropped to around $40 \mathrm{MPa}$ in P-ETO and P-ESO and $107 \mathrm{MPa}$ 
for P-ELO in the rubbery state, Table 4. Cross-link density, $\mathrm{M}_{\mathrm{c}}$, estimated from the $\mathrm{E}$ ' in the rubbery state was calculated from the relationship

$$
G=\frac{n}{V} R T=v R T=\frac{\rho}{M_{c}} R T
$$

Equation (1) is valid for networks having long enough network chains to form random coils, which was not the case here. Nevertheless, the values for $\mathrm{M}_{\mathrm{c}}$ given in Table 4 are rather low but consistent with high modulus of the networks in the rubbery state.

Loss modulus-temperature curves display a weak maximum at the position of $\beta$-relaxation and do not show a peak at the $\alpha$-transition, however, the tan $\delta$-temperature curves clearly show distinct peaks for both. The temperature for the $\alpha$-transition of P-ELO at $59{ }^{\circ} \mathrm{C}$ reflects the highest cross-link density. P-ETO displays an $\alpha$-peak at the same temperature as P-ESO ( 20 ${ }^{\circ} \mathrm{C}$ ) despite lower functionality, possibly the result of better chain packing in the more regularly structured ETO polymer. A broad $\alpha$-transition reflects wide distribution of cross-link densities in all networks. The nature of $\beta$-transition is not clear, but it depends strongly on cross-link density, being the lowest $\left(-80^{\circ} \mathrm{C}\right)$ for P-ETO and the highest for P-ELO $\left(-23^{\circ} \mathrm{C}\right)$. One could speculate that this effect is related to the rotation of short ether segments. We should bear in mind that the networks contain about $2 \%$ of toluene added with the catalyst, which together with dangling chains introduce extra free volume. The energy of activation, $E_{a}$, for each $\alpha-$ transition was estimated from DMA curves run at three frequencies $(3,10$ and $30 \mathrm{~Hz})$. The shift of the peak temperatures vs. frequency allows for the calculation of $E_{a}$ from the Arrhenius equation:

$$
\ln f=\ln f_{o}-\mathrm{E}_{\mathrm{a}} / \mathrm{RT}
$$

The $E_{a}$ values of $\alpha$-transition for three networks from DMA measured at 3, 10 and $30 \mathrm{~Hz}$ in dual cantilever mode were $355 \mathrm{~kJ} / \mathrm{mol}$ for P-ETO, $381 \mathrm{~kJ} / \mathrm{mol}$ for P-ESO and $405 \mathrm{~kJ} / \mathrm{mol}$ for P-ELO. These high $\mathrm{E}_{\mathrm{a}}$ values are consistent with high energy required for cooperative motions of crosslink segments in a highly cross-linked network structure. Similar values for P-ETO and P-ESO despite the higher epoxy group content of the latter, suggests that the regularity of the P-ETO structure plays an important role. 

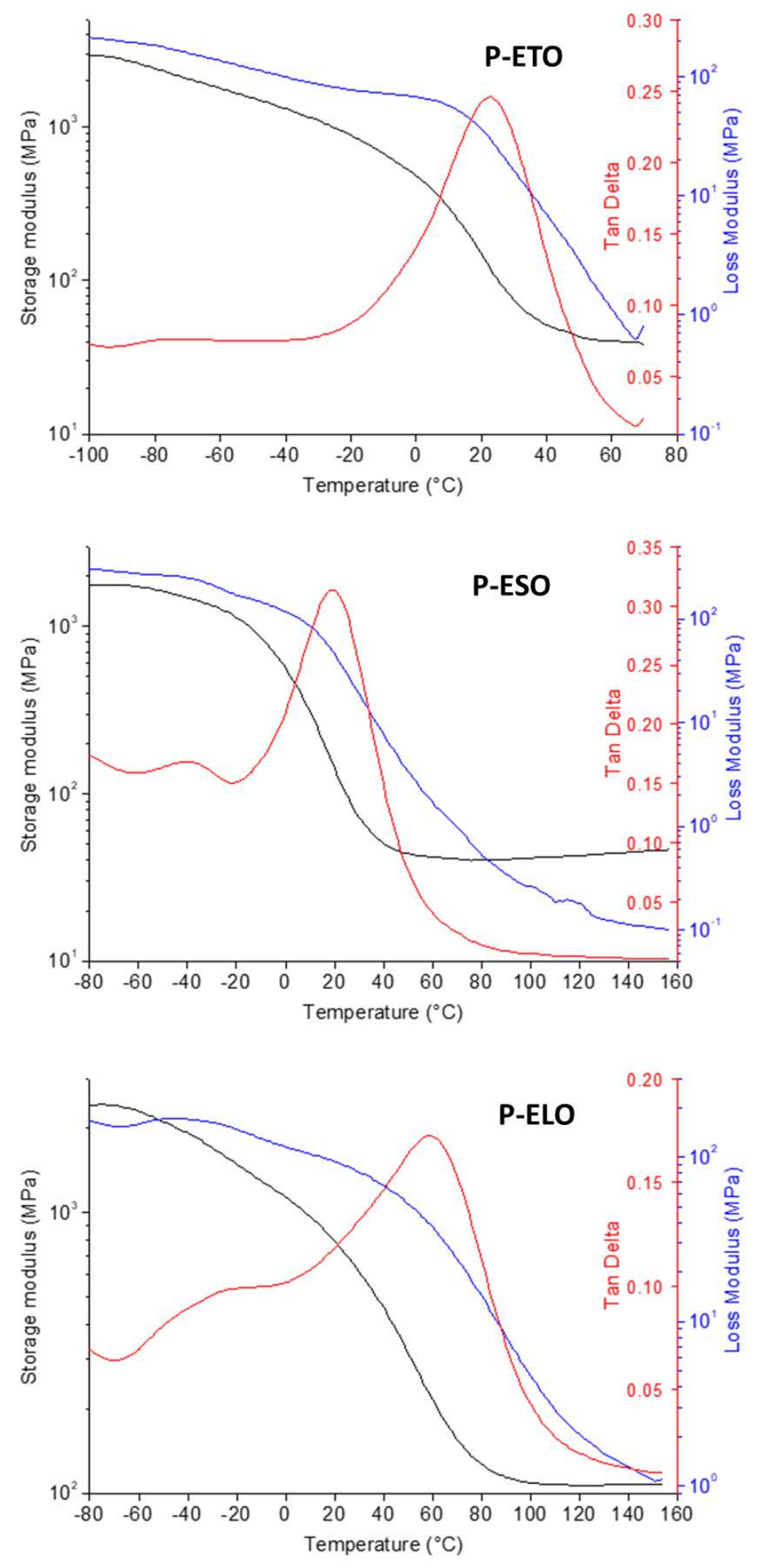

Fig. 5 Storage modulus, E', loss modulus, E", and $\tan \delta$ dependence on temperature for three cross-linked epoxidized oils. 
Table 4. Dynamic mechanical properties of polymerized epoxidized oils

\begin{tabular}{lccc}
\hline Property & P-ETO & P-ESO & P-ELO \\
\hline Glassy E', MPa & 2930 & 1780 & 2420 \\
Rubbery E', MPa & 40 & 41 & 107 \\
$\boldsymbol{\alpha}^{\prime}$ transition temp, ${ }^{\mathbf{0}} \mathbf{C}$ & 23 & 19 & 59 \\
$\boldsymbol{\beta}$-transition temp, ${ }^{\mathbf{0}} \mathbf{C}$ & -80 & -41 & -23 \\
$\mathbf{M}_{\mathbf{c}}$ (g/mol) & 201 & 213 & 96 \\
\hline
\end{tabular}

Drop in modulus from glassy to rubbery state was about two orders in magnitude for P-ETO and P-ESO, but only one order for P-ELO, characteristic for the high degree of cross-linking in all networks but particularly in P-ELO.

\section{Dielectric properties of polymers}

Compared to DMA dielectric analysis reveals molecular motions in a much wider frequency range. Change of relative permittivity and $\tan \delta$ vs. temperature at six frequencies for the three polymers is shown in Fig. 6. Permittivity in the glassy region (up to $-20{ }^{\circ} \mathrm{C}$ ) is around 2.5 , decreasing little with increasing frequency. These values are comparable with those for nonpolar polymers. The values for P-ELO were slightly higher. The outliers were the curves at $100 \mathrm{kHz}$ for unexplained reasons. Segment-dipoles rotation increases when passing through the glass transition region resulting in increased permittivity to around 3.0-3.5 in the rubbery state. The upswing on some low-frequency curves was attributed to ionic conduction. Tan $\delta$ temperature curves display two transitions: $\alpha$ at $20-40{ }^{\circ} \mathrm{C}$ for P-ETO and P-ESO and at $\sim 60{ }^{\circ} \mathrm{C}$ for P-ELO, and very weak $\beta$ - relaxation. 

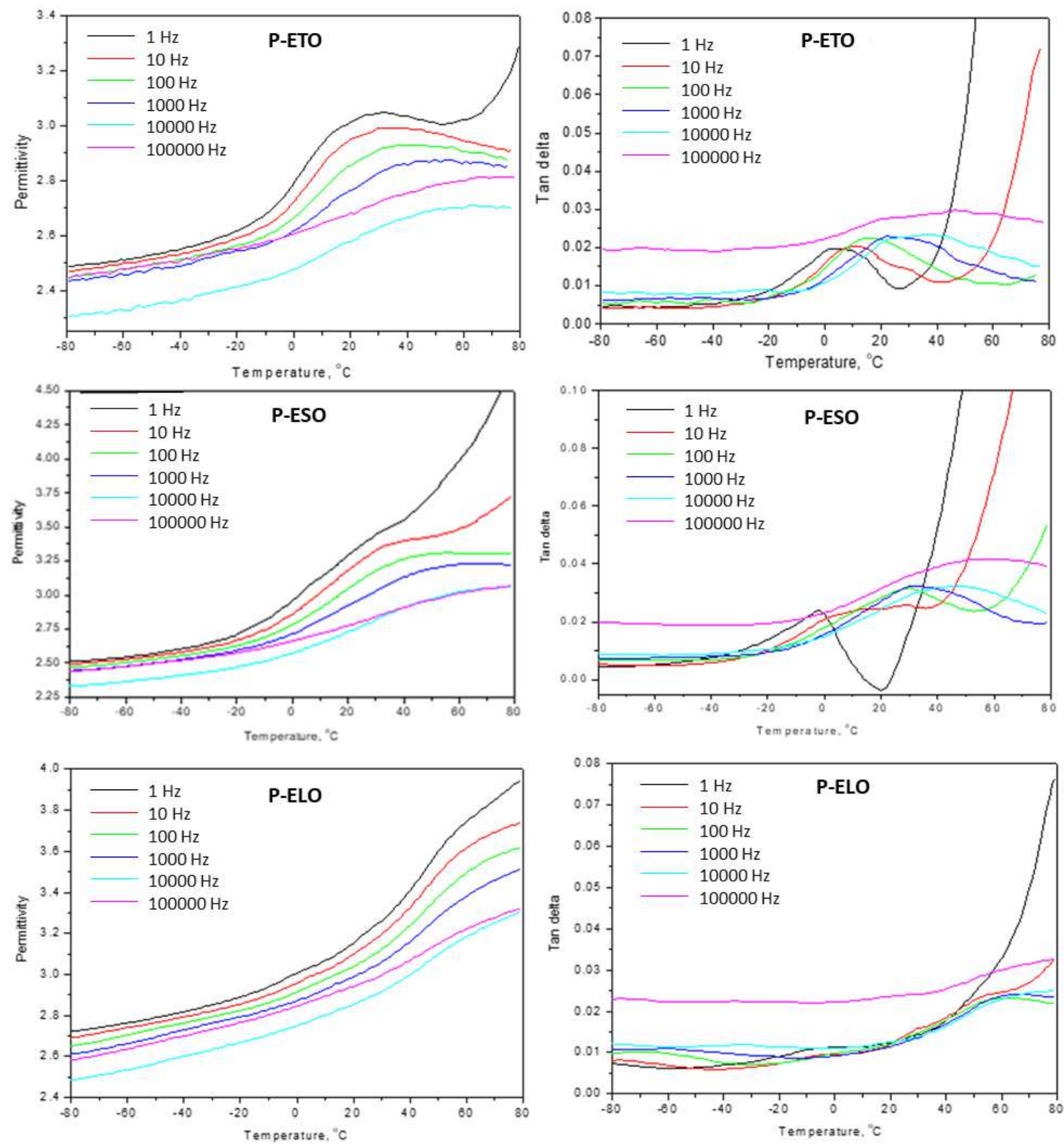

Fig. 6 Permittivity and $\tan \delta$ curves vs. temperature and frequency for P-ETO, P-ESO and PELO polymers

\section{Electrical properties}

Since the catalyst was left in the material it was suspected that it could increase conductivity of these materials. However, standard ASTM tests for electrical properties of the P-ESO carried 
out by a commercial laboratory showed very good dielectric strength of $232 \mathrm{kV} / \mathrm{cm}$, volume resistivity $1.1 \times 10^{15} \Omega \cdot \mathrm{cm}$ and surface resistivity of $5.2 \times 10^{15} \Omega /$ square, comparable with those of standard polymeric insulating materials [20]. Similar properties are expected for P-ETO and P-ELO.

\section{Stress-strain properties of networks}

Mechanical properties of polymerized epoxidized oils were to our knowledge not described before. Crivelo et al [19] used photocured epoxidized linseed oil as a binder for glass reinforced composites and studied properties of composites but not of the resin itself. Our tensile tests for polymerized epoxidized oils display an almost linear relationship between stress and strain for up to about $4 \%$ elongation and brittle fracture. Surprisingly, these materials have high hardness even in the rubbery state (at room temperature), which is measurable only on the Shore D scale. Young modulus values for P-ETO and P-ESO are high compared to typical rubbers, but the modulus for P-ELO is an order of magnitude higher, comparable to that of low-density polyethylene, and consistent with high cross-link density. Table 5 displays mechanical properties of the polymerized epoxidized oils. It appears that unusual properties of these polymers, like high transparency, low $\mathrm{T}_{\mathrm{g}}$, relatively low tensile strength and elongation but high modulus and hardness in the rubbery state, arise from the aliphatic nature of oils and lack of strong intermolecular forces (no hydrogen bonding), high cross-link density, amorphous structure and the presence of dangling chains. Fig. 7 illustrates flexibility and transparency of a $5 \mathrm{~mm}$ thick plaque of P-ESO ("solid soybean oil") polymerized with BCF.

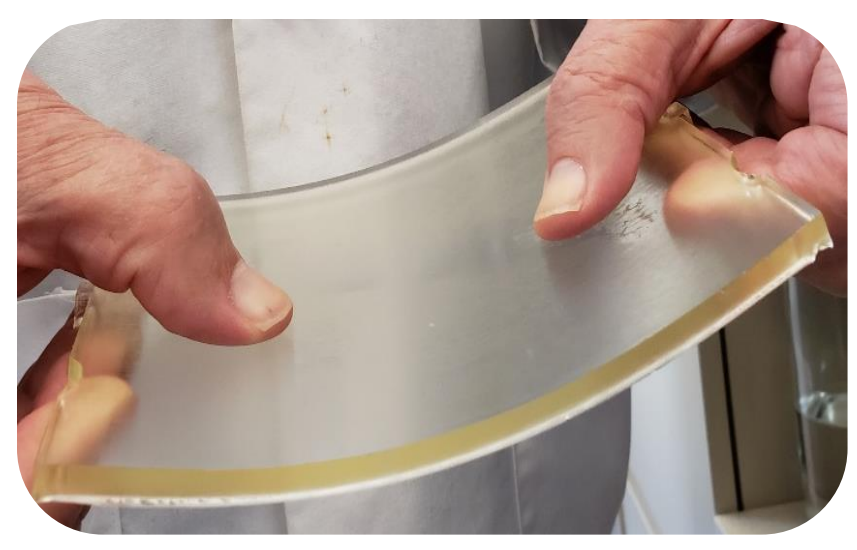

Fig. 7 The sample of epoxy resin prepared from ESO with BCF 
Table 5. Physical properties of polymerized epoxidized oils

\begin{tabular}{lccc}
\hline Property at $25^{\circ} \mathbf{C}$ & P-ETO & P-ESO & P-ELO \\
\hline T $_{\mathbf{g}}\left({ }^{\circ} \mathbf{C}\right)$, DSC & 5 & 3 & 44 \\
Tensile strength, MPa & 1.9 & 3.3 & 14 \\
Elongation, \% & 9.2 & 6.1 & 5.8 \\
Young modulus, MPa & 35 & 34 & 350 \\
Shore Hardness A/D & $96 / 50$ & $100 / 75$ & $97 / 56$ \\
\hline
\end{tabular}

\section{Thermal stability of polymerized epoxidized oils in nitrogen}

Thermal stability of polymerized epoxidized oils is best illustrated by TGA of P-ETO (Fig. 8). The material does not show any significant weight loss below $335^{\circ} \mathrm{C}$. The small amount of toluene seems to have been lost after the polymerization during the heat curing. Degradation is expected to start at weak links in the structure: ester bonds from oils and ether bonds formed by polymerization of epoxides. Once these processes start, the polymer loses weight completely by $450{ }^{\circ} \mathrm{C}$.

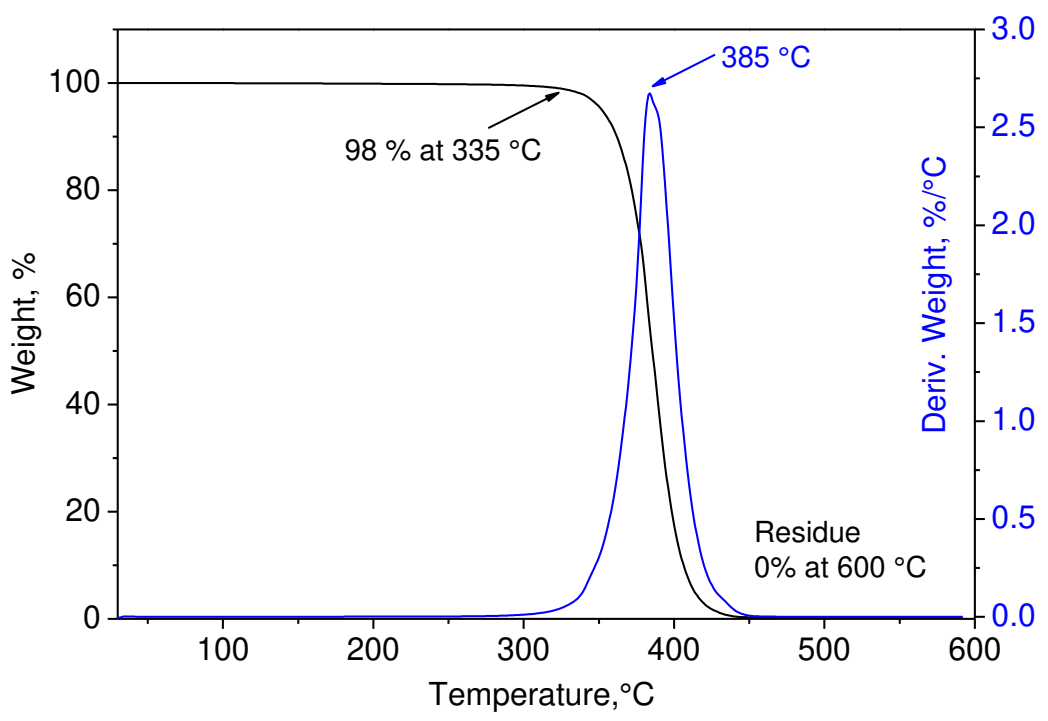

Fig. 8 TGA of polymerized ETO network in nitrogen.

\section{Conclusions}

A novel catalyst for the cationic polymerization of triglycerides with internal epoxides was used at very low concentration to prepare $100 \%$ oil-based polyethers (epoxy resins) from epoxidized triolein, epoxidized soybean and epoxidized linseed oils. This polymerization 
process starts at room temperature and the catalyst resin mixture shows sufficient pot life for processing. Using increased temperature allows faster gelation, perhaps useful for 3D printing. The resulting materials are highly cross-linked, amorphous, transparent, and relatively brittle, with excellent electrical properties. Mechanical properties and glass transition increased with higher epoxy content. Dangling chains acted as plasticizers, rendering rubbery polymers at room temperature. These $100 \%$ oil-based materials are potentially useful as encapsulating and potting compounds for electronic applications.

\section{Acknowledgment}

We are indebted to the Kansas Soybean Commission and Honeywell for the partial funding of this work.

\section{Compliance with Ethical Standards}

Conflict of interest There is no conflict of interest by any of the authors. 


\section{References}

1. Radojčić D, Hong J, Ionescu M, Wan X, Javni I, Petrović ZS. Study on the reaction of amines with internal epoxides. Eur J Lipid Sci Technol. 2016;118:1507-11.

2. Roesch J, Muelhaupt R. Polymers from renewable resources: polyester resins and blends based upon anhydride-cured epoxidized soybean oil. Polymer Bulletin: (Berlin). 1993;31 (6): 679-85.

3. Hong D, Javni I, Petrović ZS. Vegetable Oil Based Epoxy Resins. SAMPE fall technical conference \& exhibition; October 19-22; Wichita, KS, USA 2009.

4. España JM, Sánchez-Nacher L, Boronat T, Fombuena VF, Balart R. Properties of Biobased Epoxy Resins from Epoxidized Soybean Oil (ESBO) Cured with Maleic Anhydride ). J Am Oil Chem Soc 2012;89:206775.

5. Crivello JV, Narayan R. Epoxidized triglycerides as renewable monomers in photoinitiated cationic polymerization. Chemistry of Materials. 1992;4(3):692-9.

6. Warwel S, Fehling E, Kunz M. Photoinitiated cationic oligomerization of therminal and internal epoxides. Eor. J. Lipid Sci. Technol. 2001; 103:133-40.

7. LLigadas G, Ronda JC, Galia M, Biermann U, Metzger JO. Synthesis and characterization of polyurethanes from epoxidizaed methyl oleate based polyether polyols as renewable resources. . J Polymer Science: Part A: Polym Chem. 2006;44(634-645).

8. Biswas A, Liu Z, Cheng HN. Polymerization of epoxidized triglycerides with fluorosulfonic acid. International Journal of Polymer Analysis and Characterization. 2016;21 (1):85-9. doi:10.1080/1023666X.2016.1110353

9. Petrović ZS, Javni IJ, Ionescu M, Cvetkovićl, Zlatanić A, Bilić $\mathrm{N}$ et al., inventors; CertainTeed, assignee. FOAM, COMPOSITION, AND METHOD. US Pat 9,487,654 B2. 2016 Nov 8.

10. Radojčić D, Petrović ZS, Tanasić J, Ristić I. Filled Epoxy Resins from Natural Oils. J Polym Environ 2020;28:1292-301. doi:10.1007/s10924-020-01689-9.

11. Radojčić D, lonescu M, Petrović ZS. Cationic polymerization of model epoxidized compounds with B(C6 F5)3,. J Polym Environ. 2019. doi:10.1007/s10924-020-01984-5.

12. Lawson JR, Melen RL. Tris(pentafluorophenyl)borane and Beyond: Modern Advances in Borylation Chemistry. Inorg Chem 2017; 56:8627-43. doi:https://doi.org/10.1021/acs.inorgchem.6b02911.

13. Petrović ZS, Zlatanić A, Lava CC, Sinadinović-Fišer S. Epoxidation of soybean oil in toluene with peroxoacetic and peroxoformic acids - kinetics and side reactions. Eur J Lipid Sci Technol 2002;104 (5):293-9. 
14. SavioBranciforti D, SimoneLazzaroni, ChiaraMilanese, MarcoCastiglioni, FerdinandoAuricchio, DarioPasini et al. Visible light 3D printing with epoxidized vegetable oils. Additive Manufacturing. 2019;25:317-24. doi: https://doi.org/10.1016/j.addma.2018.11.020.

15. Xu Y, Petrović ZS, Das S, Wilkes GL. Morphology and Properties of Thermoplastic Polyurethanes with Dangling Chains in Ricinoleate-Based Soft segments. Polymer. 2008;49:4248-58.

16. Bantchev GB, Doll KM, Biresaw G, Vermillion KE. Formation of Furan Fatty Alkyl Esters from their Bis-Epoxide Fatty Esters. J Am Oil Chem Soc 2014;91:2117-23.

17. van Krevelen DW. Properties of Polymers. 3 ed. New York: Elsevier; 1990.

18. Liu Z, Biswas A. Fluoroantimonic acid hexahydrate (HSbF6.6H2O) catalysis: The ring-opening polymerization of epoxidized soybean oil, Applied Catalysis A: General Applied Catalysis A: General 2013;453 370- 5. doi:http://dx.doi.org/10.1016/i.apcata.2012.12.028.

19. Crivello JV, Narayan R, Sternstein SS. Fabrication and mechanical characterization of glass fiber reinforced UV-cured composites from epoxidized vegetable oils. J Appl Polym Sci. 1997;64:2073-87. 20. Modern Plastics Handbook,. New York: McGraw-Hill; 2000. 
Figures

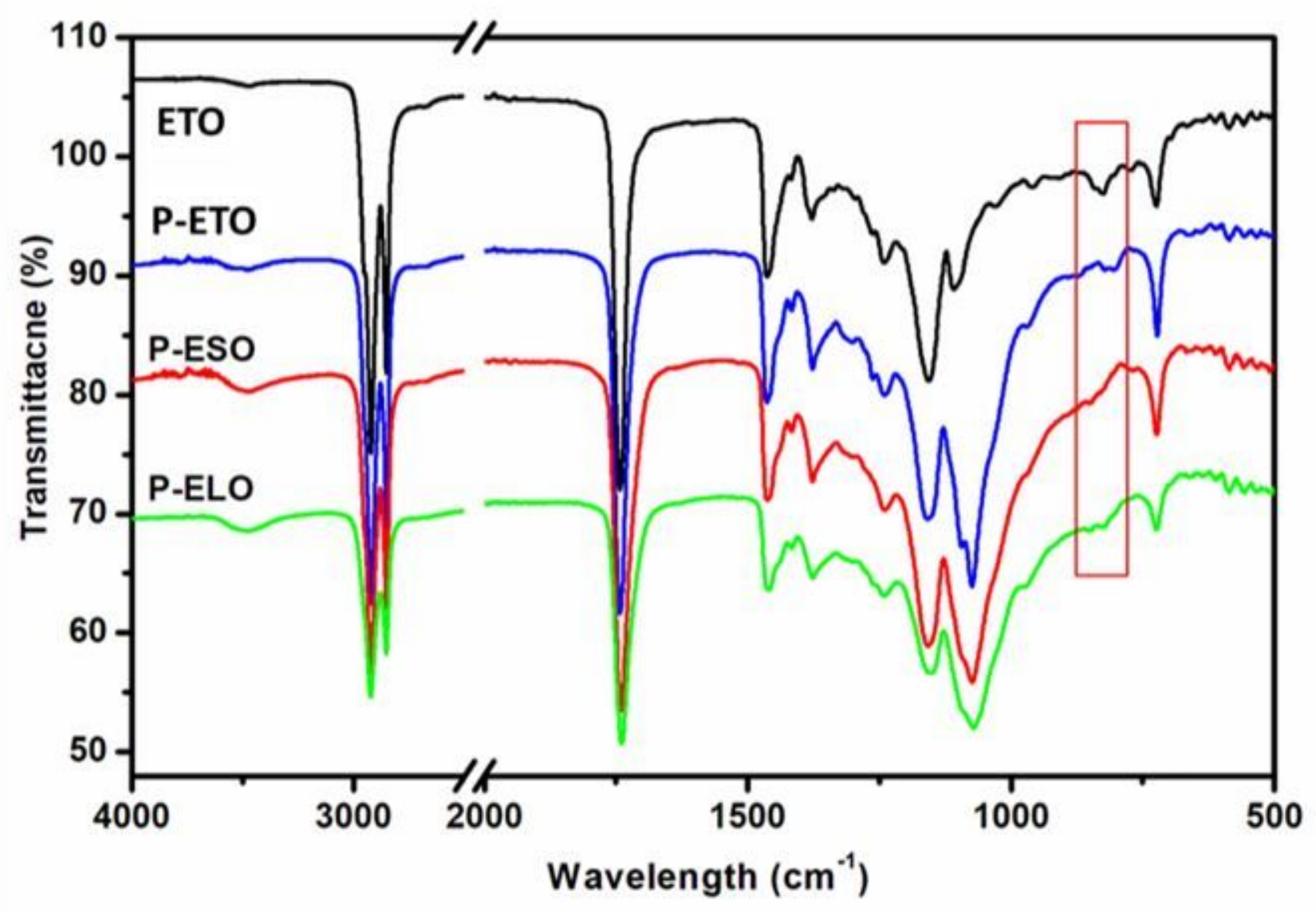

Figure 1

Infrared spectra of P-ETO, P-ESO, P-ELO, and ETO reference. Epoxy bands if present should appear in the box. 


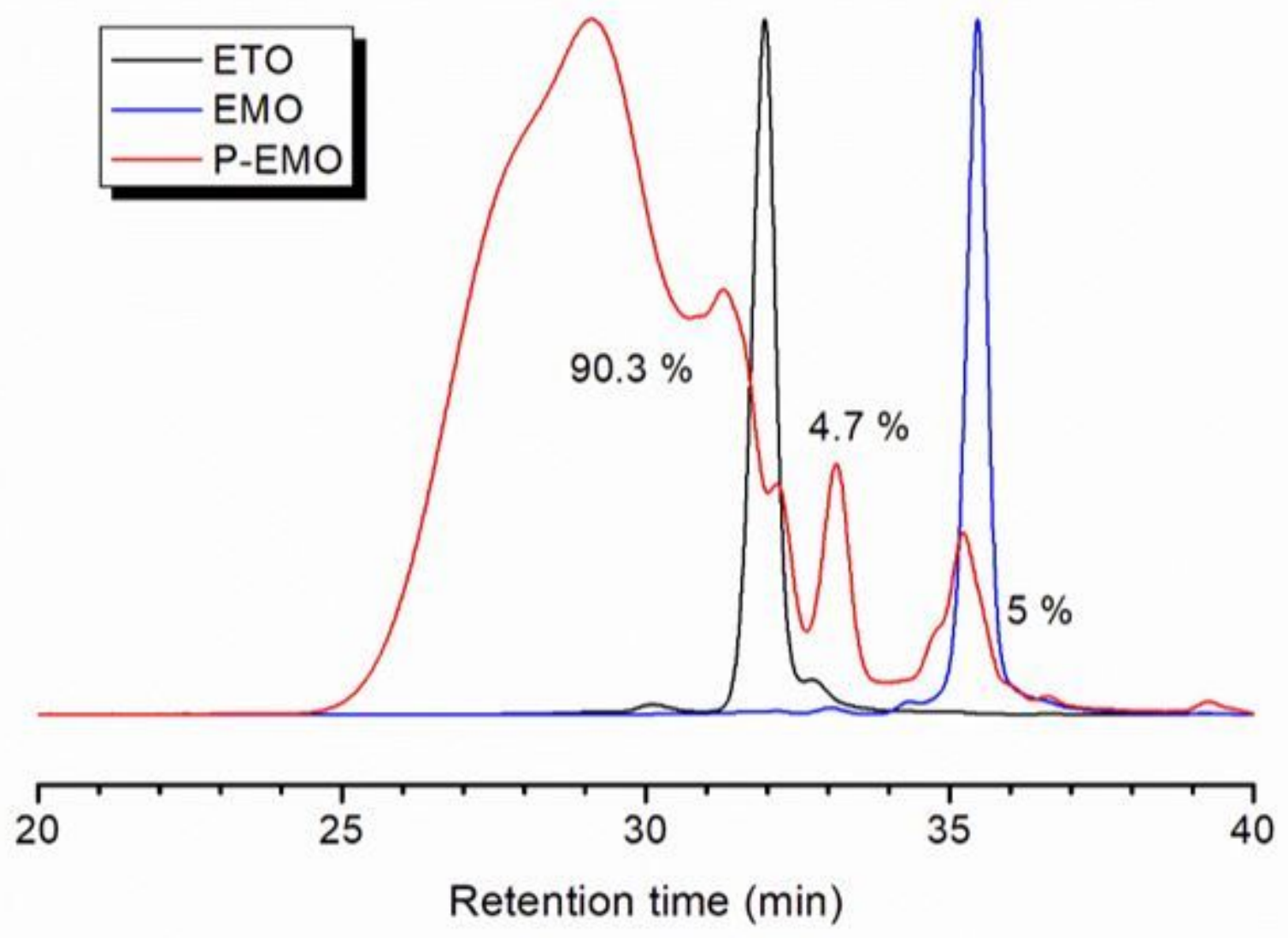

Figure 2

SEC curves for the hydrolyzed ETO polymer (P-EMO), epoxidized triolein (ETO) and epoxidized methyl oleate (EMO). 


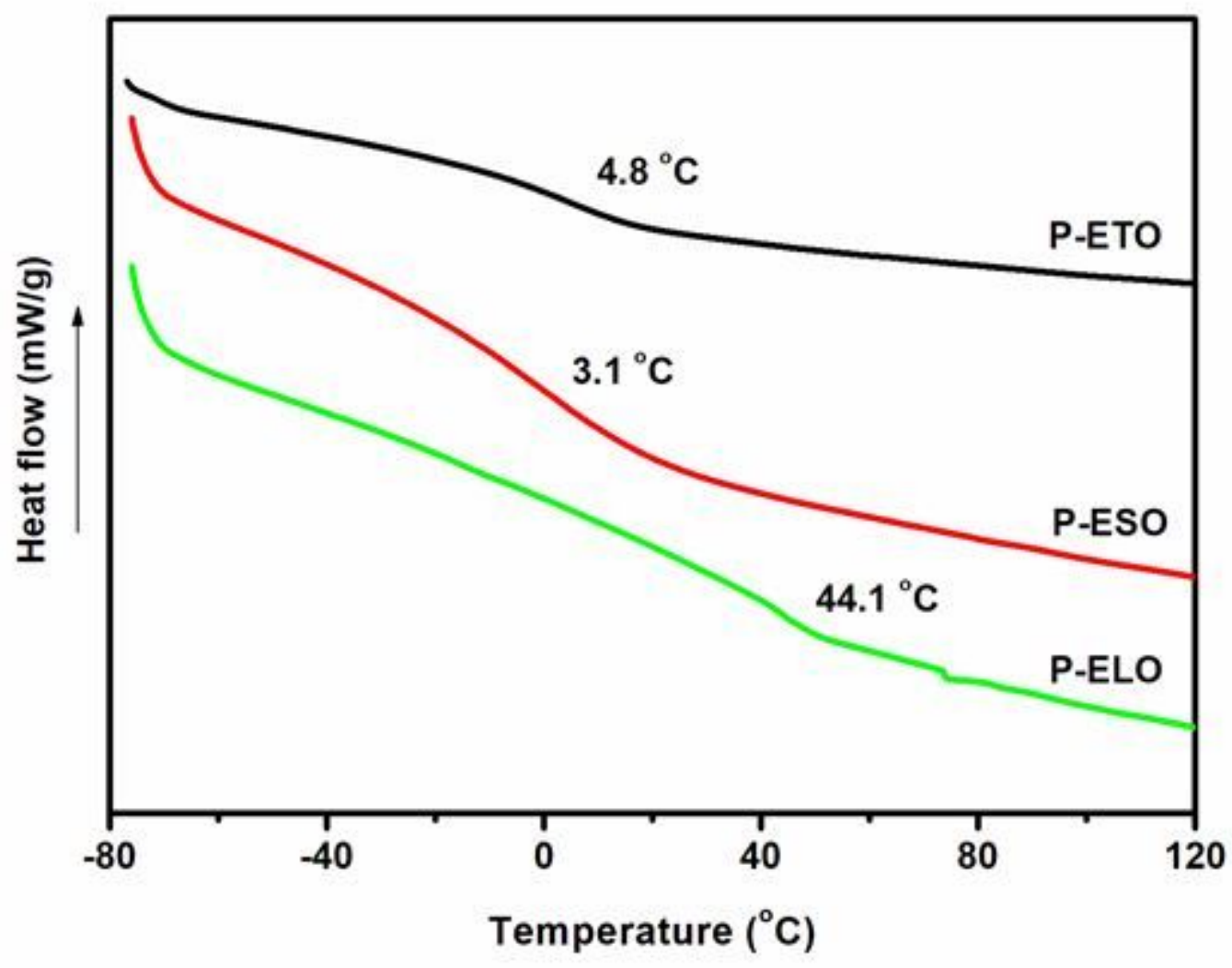

Figure 3

DSC curves for polymerized P-ELO, P-ESO and P-ETO 


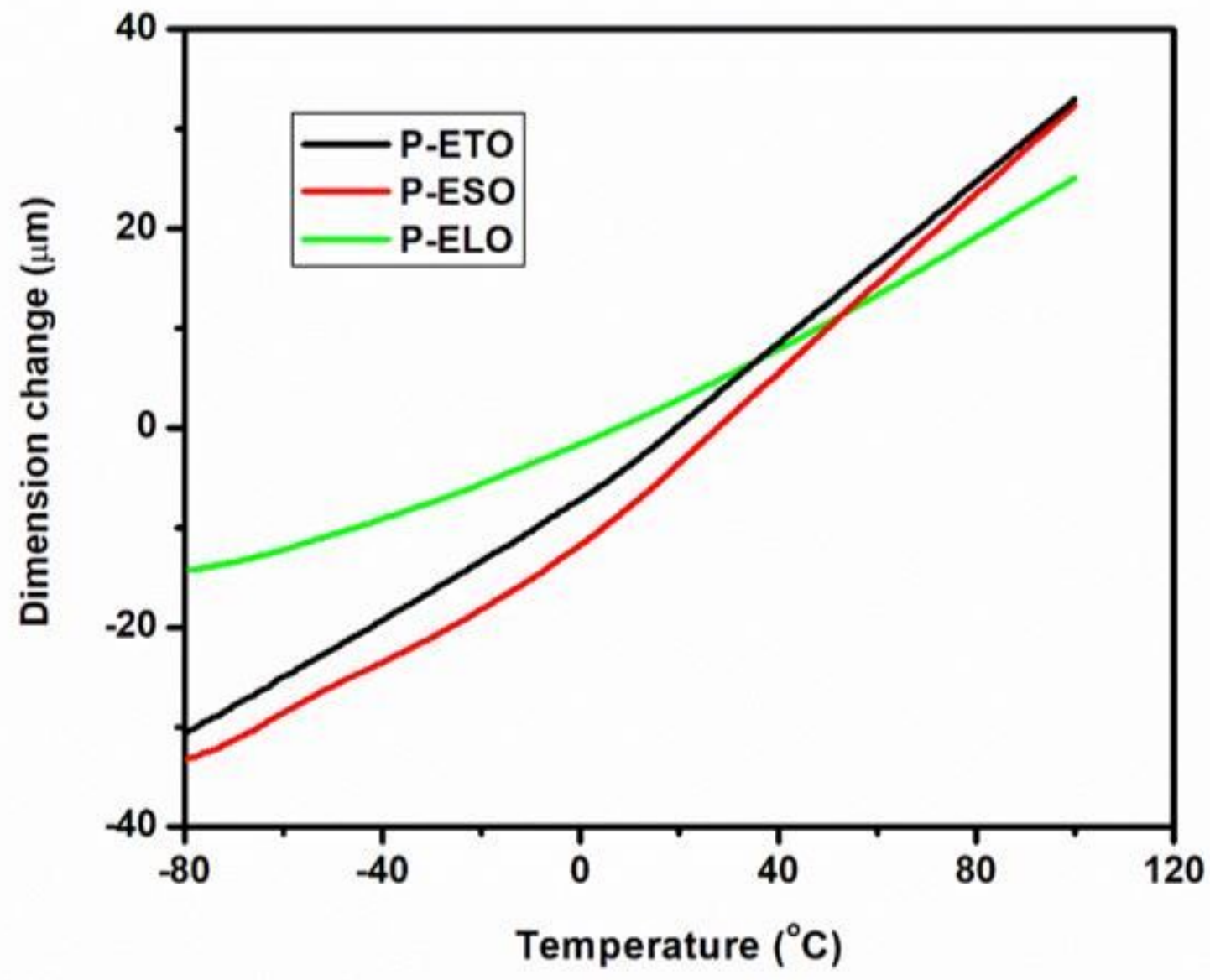

Figure 4

Thermal expansion curves for polymerized P-ELO, P-ESO and P-ETO 

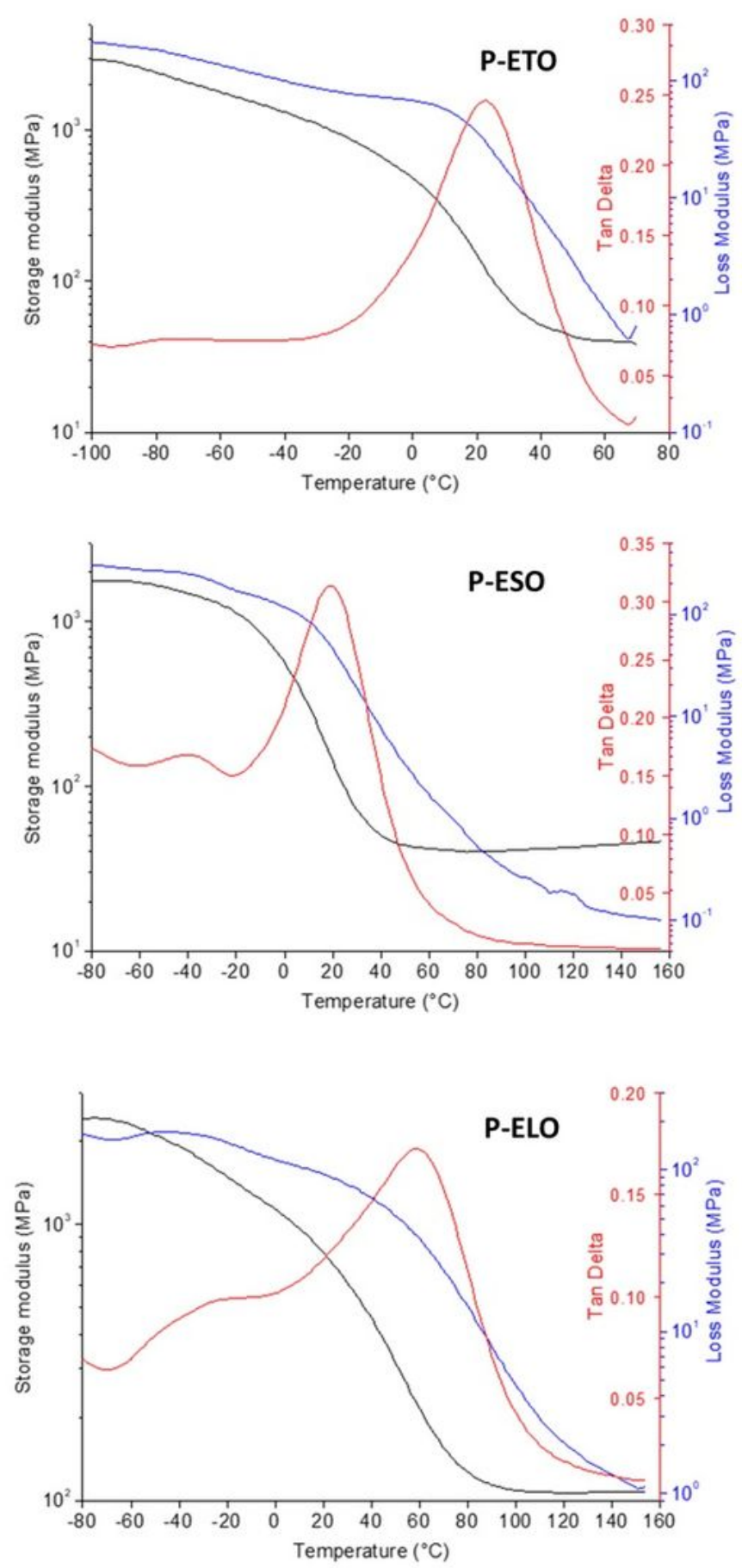

Figure 5

please see the manuscript file for the full caption 

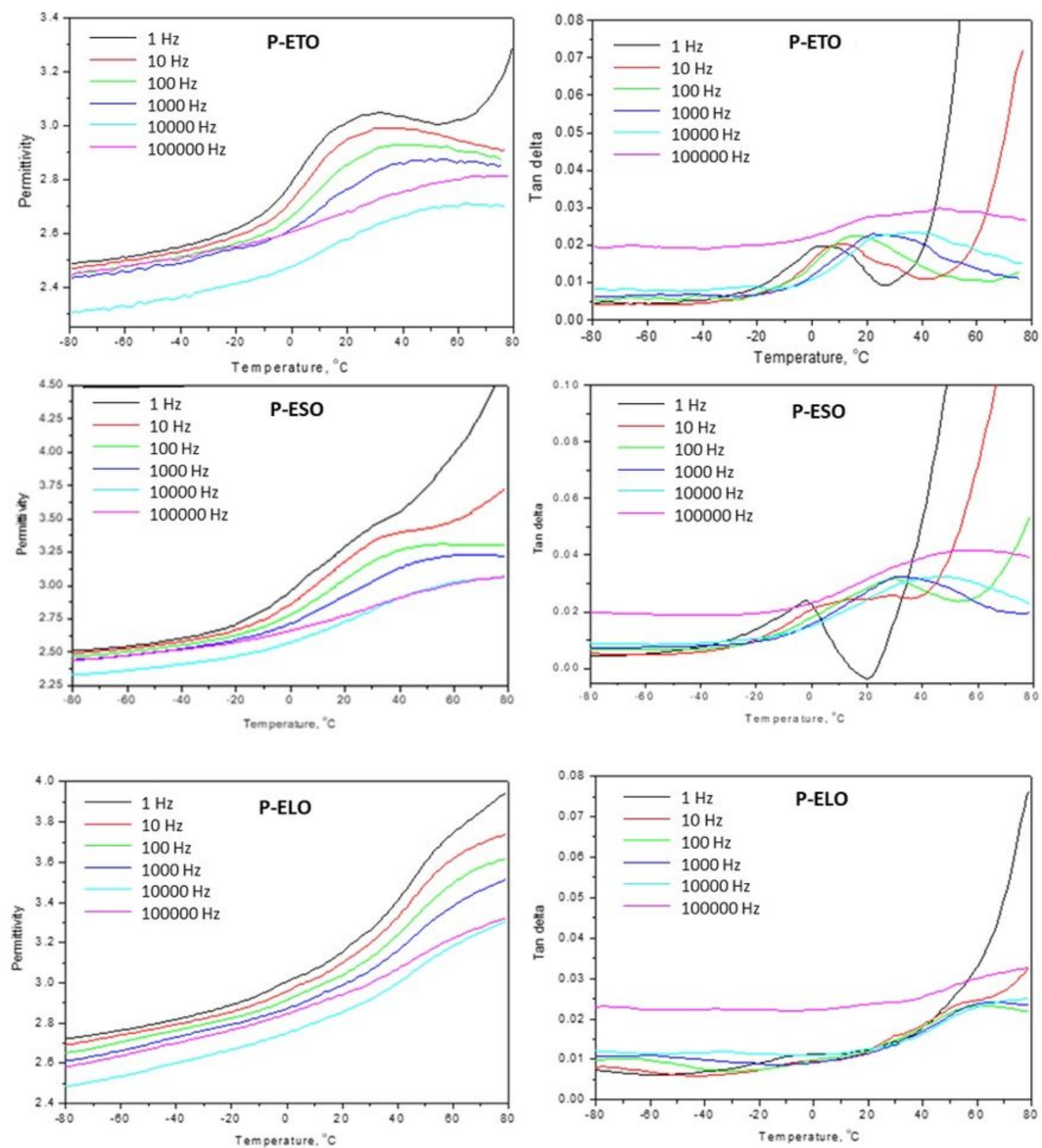

Figure 6

please see the manuscript file for the full caption 


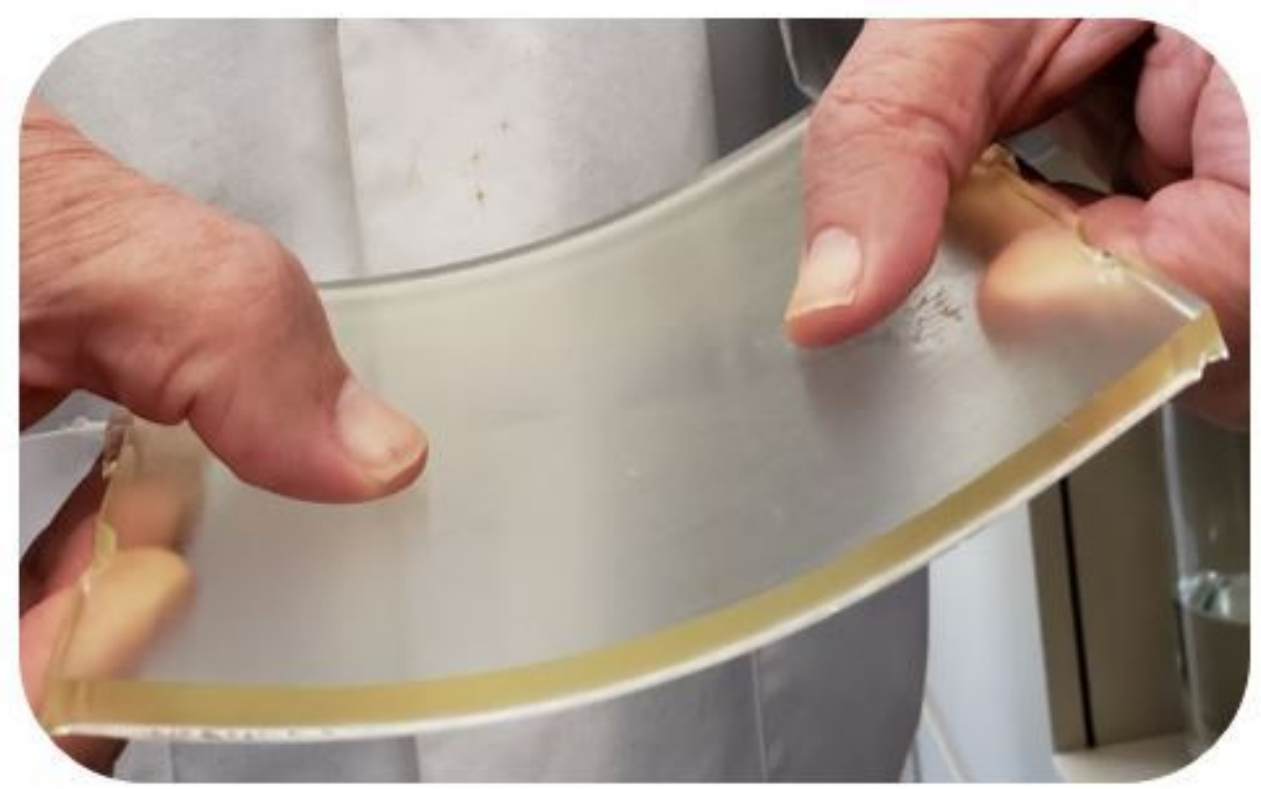

Figure 7

The sample of epoxy resin prepared from ESO with BCF

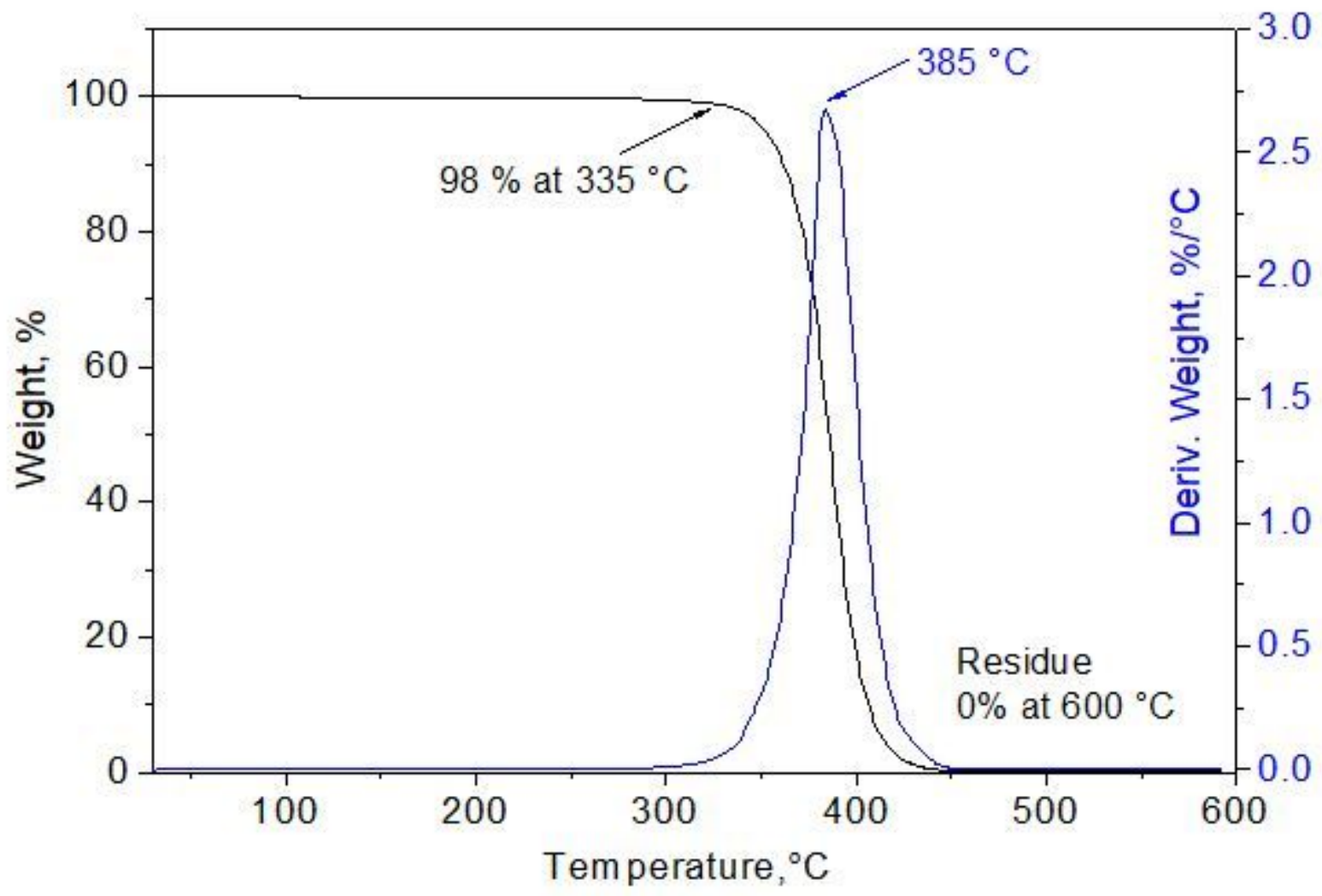

Figure 8

TGA of polymerized ETO network in nitrogen. 


\section{Supplementary Files}

This is a list of supplementary files associated with this preprint. Click to download.

- s3.jpg

- S4.jpg

- scheme1.jpg

- scheme2.jpg 